\title{
The effects of age-at-maturation on the parameters of a biphasic Lester growth model in Sander lucioperca
}

\author{
Jyrki Lappalainen ${ }^{1, *}$, Mika Vinni $^{1} \&$ Tommi Malinen ${ }^{2}$ \\ 1) Faculty of Biological and Environmental Sciences, Ecosystems and Environment Research \\ Programme, P.O. Box 65, Fl-00014 University of Helsinki, Finland (*corresponding author's \\ e-mail: jyrki.t.lappalainen@helsinki.fi) \\ 2) Lammi Biological Station, University of Helsinki, Pääjärventie 320, Fl-16900 Lammi, Finland
}

Received 1 Oct. 2020, final version received 10 Dec. 2020, accepted 9 Dec. 2020

Lappalainen, J., Vinni, M. \& Malinen, T. 2021: The effects of age-at-maturation on the parameters of a biphasic Lester growth model in fish. - Ann. Zool. Fennici 58: 13-29.

An accurate estimation of growth is crucial for any fish species that is a target in fishery. We applied a biphasic Lester model for pikeperch (Sander lucioperca) population that is a slow-growing one. In this model, age at maturity divide the growth into immature and matuire phases. Logistic regression models showed that both age and length were significant in males and females when using maturity as a dependent variable, and both of these variables differed between sexes. To estimate how the changes in used age at maturity affect the Lester model parameters, the effects of ages from $10 \%$ to $90 \%$ probability of maturity were analysed. The gonadosomatic index of males (max. $2 \%$ ) and females (max. 8.6\%) was used to select Lester models that also gave low estimates for the investments in reproduction $(g)$. Low $g$ values were found in the Lester models for ages from $60 \%$ to $90 \%$ probability of maturity in males, and from $30 \%$ to $70 \%$ in females.

\section{Introduction}

The somatic growth of fish can be classified into two distinctive phases: a pre-maturity phase in which all excess energy is used for somatic growth, and a post-maturity phase in which some or all excess energy is allocated for reproduction (Day \& Taylor 1997). Lester et al. (2004) developed a growth model based on these two phases: the growth of immature fish can be estimated with a linear model, while the growth of mature fish follows that of the von Bertalanffy growth model. Compared with the von Bertalanffy model, the Lester model is a mechanistic growth model that allows the amount of energy invested in reproduction to be estimated. Moreo- ver, Shuter et al. (2005) showed that this investment is also linked to other life history variables such as total mortality. However, when applying the Lester model, it is very important to assess the age at maturity correctly, because this divides the model into two categories.

The species studied by us is the slow-growing pikeperch (Sander lucioperca) in Sahajärvi, a lake in Finland (Vinni et al. 2009, Milardi et al. 2011). Olin et al. (2018) showed that the slow-growing female pikeperch matured at an older age but smaller size than the fast-growing ones. Aside from the growth rate, the first females matured three years earlier than the last ones (Olin et al. 2018). Thus, assigning one age at maturation to the entire population is not accu- 
rate, as it rarely fits all individuals (Lehtonen 1987, Raikova-Petrova \& Živkov 1998, Lappalainen et al. 2003, Ruuhijärvi et al. 2005). This can be problematic when applying the biphasic Lester model. This model is usually estimated only for females (e.g. Shuter et al. 2005, Rennie \& Venturelli 2015, Honsey et al. 2017) or for pooled sexes (Vainikka et al. 2017), while studies of male growth are rare (Enberg et al. 2008, Rennie et al. 2008).

The immature phase ends when the investment in reproduction begins. In pikeperch, the intense feeding period before the onset of the reproductive cycle, i.e. May-July, seems crucial for pikeperch to store enough energy to be able to start and complete their entire gametogenesis (Teletchea et al. 2009). Gonads mature during the late autumn or winter (Teletchea et al. 2009, M'Hetli et al. 2011, Fontaine et al. 2015) and spawning takes place the following spring (April to June, depending on the latitude) (Lappalainen et al. 2003). Hence, the investment in reproduction already started during the previous year, which should be taken into account when determining the age at maturity (Wilson et al. 2018).

Here, the main aim was to analyse the growth of pikeperch with the Lester model. Pikeperch in Sahajärvi is known to be an exceptionally slow-growing one (Milardi et al. 2011) compared with other pikeperch populations (Lappalainen \& Malinen 2002). The fitting of Lester model requires information on age at maturity. Therefore, our first aim was to estimate age and length at maturation for each sex separately, and then for the pooled sexes. We were particularly interested in determining whether length is an important factor in the onset of maturation in males, as has been found for female pikeperch (Olin et al. 2018). If length is a significant factor in maturation, and not all pikeperch mature at the same age (Lehtonen 1987, Raikova-Petrova \& Živkov 1998, Olin et al. 2018), we hypothesized that the mature pikeperch will be either longer or heavier than immature pikeperch of the same age. Our second aim was to evaluate how setting the age at maturity affects the parameters in the Lester model. This was done first by separating the sexes, and then by pooling all available data.

\section{Material and methods}

\section{Pikeperch sampling, age determination and maturity}

Pikeperch samples were collected with different types of gear in 2016 and 2017 from Sahajärvi, a lake in Finland. A seine was used to collect the samples for maturity estimations before the pikeperch spawning (May 2017), whereas the growth was estimated from samples collected with several types of gear, mainly gillnets (Table 1).

In the laboratory, pikeperch were measured (total length, TL, mm) and weighed $(\mathrm{g})$, and 10-20 scales were taken from the area between the lateral line and pelvic fin. Scales were used in age determination and to back-calculate lengths. The age determinations were also compared with those based on the sagittae otoliths, especially in larger and older pikeperch. Otoliths were roasted with flame to coffee-brown and broken into two parts across the nucleus. Then the age was determined from otolith's broken surface (Tolonen et al. 1999). Since roughly half of

Table 1. Number of pikeperch $(n)$ caught with different gear. Mesh sizes from knot to knot.

\begin{tabular}{|c|c|c|c|}
\hline Gear & Dimensions & Period & $n$ \\
\hline Seine & $\begin{array}{l}\text { Height } 7 \mathrm{~m} \text {, wing } 150 \mathrm{~m} \text { each with } \\
\text { mesh size } 10 \mathrm{~mm} \text { and } 6 \mathrm{~mm} \text { in bag }\end{array}$ & May 2017 & 206 \\
\hline Nordic gillnet & $\begin{array}{l}\text { Twelve } 1.5 \mathrm{~m} \times 2.5 \mathrm{~m} \text { panels with } \\
\text { mesh sizes of } 5,6.25,8,10,12.5, \\
15.5,19.5,24,29,35,43 \text {, and } 55 \mathrm{~mm}\end{array}$ & August 2017 & 148 \\
\hline Gillnet & $\begin{array}{l}\text { Length } 30 \mathrm{~m} \text {, height } 1.8 \mathrm{~m} \text {, mesh } \\
\text { sizes between } 20 \text { and } 60 \mathrm{~mm}\end{array}$ & July, September 2017 & 83 \\
\hline Gillnet, wire trap & Different types & June-November 2016, April-May 2017 & 23 \\
\hline
\end{tabular}


the pikeperch were caught during the growing season, the back-calculated lengths at the end of the previous growing season were used in the growth models, i.e. only one back-calculated length per pikeperch was used. Length-at-age was back-calculated using the Fraser-Lee procedure (Bagenal \& Tesch 1978). A value of $44 \mathrm{~mm}$ was used as the intercept (Ruuhijärvi et al. 1996).

Maturity was evaluated from the progonads of the pikeperch. Sex of the immature pikeperch $(\mathrm{TL}>100 \mathrm{~mm}$ ) was assessed from tissue slices on glass viewed under an optic microscope (Antila et al. 1988, Winkler et al. 1989, Hermelink et al. 2011). Mature individuals were sexed by dissection and direct observation of gonads. In mature or maturing females, the progonad is filled with maturing eggs; in males, the progonad shows no recognizable elements. The gonadosomatic indices (GSI = gonad weight/ (total weight - gonad weight)) of both males and females were estimated from pikeperch caught in May (Table 1).

\section{Statistical analyses}

A $t$-test was used to compare mean lengths and weights between immature and mature pikeperch at the ages when some pikeperch were still immature and some mature. These analyses were done for each sex separately. Since the hypothesis was one-sided, i.e. mature pikeperch are either longer or heavier than the immature ones at the same age, we used a one-sided $t$-test. If the variances in the tested groups were equal, we used a pooled $t$-test; if they were unequal, a Satterthwaite $t$-test with the corresponding degrees of freedom was used instead (SAS 2015).

The age and length at maturity of pikeperch were estimated using logistic regression (SAS 2015). Maturity was estimated only for pikeperch caught in May just before the spawning (Table 1), because this is the best season to estimate maturity from gonads. These analyses started with pooled data to test whether the interaction between age and sex (male $n=64$, female $n=104$ ) is significant. Below are two examples of the logistic regression models used:

$$
y=\frac{\exp (a+b \times \text { age })}{1+\exp (a+b \times \text { age })}
$$

$y=\frac{\exp (a+b \times \text { age }+c \times \text { length }+d \times \text { age } \times \text { sex })}{1+\exp (a+b \times \text { age }+c \times \text { length }+d \times \text { age } \times \text { sex })}$,

where $y$ is maturity, expressed as 0 in immature and as 1 in mature pikeperch, age is in full years, length is the total length in $\mathrm{mm}$, sex is a categorical variable, and $a, b, c$, and $d$ are constants. In addition to the interaction between age and sex (Eq. 2), the interaction between length and sex was also analysed. Since both interactions (age $\times$ sex, or length $\times$ sex) were significant, sexes were also analysed separately. In these separate analyses, Firth's penalized likelihood approach was applied due to the separability and small sample size (Heinze 2006, SAS 2015). The use of logistic regression models enabled the probability of maturity to be estimated for those pikeperch whose maturity could not be determined based on sex, age, and length.

Logistic regression gives estimates of age or size at which a certain proportion of individuals are mature, which is different from maturation reaction norms (Barot et al. 2004). With the method used here, it is impossible to evaluate whether the observed maturation is the first in that individual's lifetime, or if it already matured in previous years (Barot et al. 2004).

\section{Lester model}

The Lester model was first fitted using data for males and females separately, and then using pooled data. This model describes immature growth with a linear model (Eq. 3), and mature growth as a von Bertalanffy (Eq. 4) curve:

$$
\begin{gathered}
l_{t}=h\left(t-t_{1}\right), \text { when } t \leq T, \text { and } \\
l_{t}=l_{\infty}\left(1-\exp \left(-k\left(a-t_{0}\right)\right)\right), \text { when } t>T
\end{gathered}
$$

where

$$
\begin{gathered}
l_{\infty}=\frac{3 h}{g}, \\
k=\log \left(1+\frac{g}{3}\right),
\end{gathered}
$$




$$
t_{0}=\frac{\log \left(1-\left(\frac{g\left(T-t_{1}\right)}{3}\right)\right)}{\log \left(1+\frac{g}{3}\right)},
$$

where $l_{t}$ is the length at age $t, h$ is the juvenile growth rate (length per unit time), $g$ is the investment in reproduction, $t_{1}$ is the hypothetical age at length $0, T$ is the last immature age, $l_{\infty}$ is the asymptotic length, $k$ is the von Bertalanffy (Brody) growth coefficient, and $t_{0}$ is the von Bertalanffy (adult) hypothetical age at length 0 .

The Lester models were fitted using the $\mathrm{R}$ code that follows the one given in Wilson et al. (2018: appendix S1). In the R code, the analyses started by the division of data into immature and mature groups. Next, a linear growth model was fitted to the immature-pikeperch data (Eq. 3). This gave estimates for $h$ and $t_{1}$. These two parameters were then used in fitting the growth for the mature group (Eqs. 5, 6 and 7). Because the age at maturity was known and estimated with logistic regression, only the investment in reproduction $(g$ ) was unknown (Eq. 5). The immature linear and mature growth joins at age $T$.

Generally, the age at $50 \%$ probability or maturity is chosen at the population level (MinteVera et al. 2016, Honsey et al. 2017). Here, the Lester models were fitted using age at $10 \%\left(A_{10}\right)$ to $90 \%\left(A_{90}\right)$ probability of maturity in $T$ based on the logistic regressions first by sexes separately, and then for the pooled all data. Preliminary analyses showed that the selected age at maturity changes the Lester model parameters, and especially when the full age changes, for example from 4 to 5 years, because then the division of pikeperch into immature and mature groups also changes. In pikeperch, the investment in reproduction is already initiated during the previous year of the actual spawning, and the lower range $\left(A_{10}-A_{40}\right)$ was selected to account for this. The use of lower range also reduces the risk of assigning mature pikeperch into the immature group, while the higher range $\left(A_{60}-A_{90}\right)$ reduce the risk of assigning immature fish into the mature group. However, it was clear that the correct grouping into immature and mature groups based on one age at maturity was impossible, because there was no single age, which could be used to assign all the pikeperch to correct groups (Table 2).

\section{Evaluation of fits of logistic regression and Lester models}

The fits of logistic regression and Lester models were evaluated with Akaike's information criterion (AICc). AICc values can be used only in

Table 2. The number of immature and mature pikeperch by sexes in relation to length class and age in May 2017.

\begin{tabular}{|c|c|c|c|c|c|}
\hline & \multicolumn{2}{|c|}{ Male } & \multicolumn{2}{|c|}{ Female } & \multirow[t]{2}{*}{ Total $n$} \\
\hline & Immature $(n=39)$ & Mature $(n=25)$ & Immature $(n=75)$ & Mature $(n=29)$ & \\
\hline \multicolumn{6}{|c|}{ Length class (TL, mm) } \\
\hline $100-150$ & 6 & - & 13 & - & 19 \\
\hline $151-200$ & 13 & - & 23 & - & 36 \\
\hline $201-250$ & 9 & - & 15 & - & 24 \\
\hline $251-300$ & 9 & 10 & 16 & 4 & 39 \\
\hline $301-350$ & 2 & 11 & 8 & 10 & 31 \\
\hline $351-400$ & - & 3 & - & 10 & 13 \\
\hline $401-450$ & - & 1 & - & 5 & 6 \\
\hline \multicolumn{6}{|l|}{ Age (years) } \\
\hline 2 & 8 & - & 17 & - & 25 \\
\hline 3 & 19 & - & 29 & - & 48 \\
\hline 4 & 1 & - & 7 & - & 8 \\
\hline 5 & 11 & 12 & 19 & 9 & 51 \\
\hline 6 & - & 9 & 3 & 7 & 19 \\
\hline 7 & - & 4 & - & 9 & 13 \\
\hline 8 & - & - & - & 3 & 3 \\
\hline 9 & - & - & - & 1 & 1 \\
\hline
\end{tabular}


comparison between models that had the same data. AICc was calculated as:

$$
\begin{gathered}
\mathrm{AIC}=-2 \log L+2 p, \\
\mathrm{AICc}=\frac{\mathrm{AIC}+2 p(p+1)}{(n-p-1)},
\end{gathered}
$$

where $\log L$ is the $\log$-likelihood, $p$ is the number of parameters in the model, and $n$ is the number of observations. Smaller AICc values indicate better fits. AICc values are not estimated in logistic models in which Firth's penalized likelihood approach is used (see https://cran.r-project. org/web/packages/brglm/index.html; Nagashima \& Sato 2017).

In the Lester models, AICc values cannot be used to evaluate the fits over the whole range of age at maturity analysed here. Even though the same pikeperch data were divided into immature and mature groups (either males, females, or the pooled data), the groups were the same only when compared models and ages were within one full year; for example, when $A_{30}=4.64$ years and $A_{50}=4.95$ years as in males. If this was not the case, then the models between $A_{50}$ and $A_{60}$ (5.10 years) cannot be compared based on AICc values. Therefore, the Lester model fits and parameters were evaluated also using three independent estimates described below.

The first independent estimate was based on GSI values for males and females in May (Table 1) and the Lester model parameter $g$ (Lester et al. 2004). GSI and $g$ are not comparable directly, because the energy content per unit wet weight of gonad is typically higher than that of somatic tissue. According to Lester et al. (2004, and references therein), the energy ratio of gonad to soma on a wet weight basis varies between 1.24 and 2.0 in different fish species. They found the best match with the energy ratio value of 1.73 between gonads and soma, which was also used here for both sexes.

The mean GSI for the mature group in the pooled data was calculated in the following way: if sex was known, then the maximum GSI of that sex was used as an individual estimate, and if sex was unknown, then the mean value for both sexes was used.

The second estimate was based on the difference in lengths between calculated length with the linear immature growth model in the Lester model and that based on the logistic regression model where length was an independent variable $\left(l_{\text {diff }} \%\right)$. First, length at selected age at maturity was evaluated based on immature growth:

$$
l_{A_{x}}=\text { intercept }+h \times T,
$$

where $x$ is the selected percentage from $10 \%$ to $90 \%, T$ is the used age at maturity, and $h$ is the corresponding growth rate (length per unit time) of immature pikeperch. The difference in lengths $\left(l_{\text {diff }} \%\right)$ between immature length $\left(l_{A_{x}}\right)$ and logistic model was calculated as:

$$
l_{\text {diff }} \%=\frac{\left(l_{A_{x}}-l_{x}\right)}{l_{A_{x}}},
$$

where $l_{A_{x}}$ is the length (TL, mm) from Eg. 10, $l_{x}$ is the estimated length (TL, mm) at the age of used probability of maturity at $A_{x}$ based on logistic regression, and $x$ the selected percentage from $10 \%$ to $90 \%$.

The third estimate was the percentage of pikeperch assigned into correct group based on their observed maturity in May. Thus, when pikeperch were divided into immature or mature group based on their age, the percentage of pikeperch that were in the correct group was calculated as:

$$
\begin{aligned}
\operatorname{Corr} \% & =\left(\left(n_{\mathrm{C}_{-} \text {imm }}+n_{\mathrm{C} \_ \text {mat }_{1}}\right) /\left(n_{\mathrm{C} \_ \text {imm }}+n_{\mathrm{C} \_ \text {mat }}\right.\right. \\
& \left.\left.+n_{\mathrm{W} \_ \text {imm }}+n_{\mathrm{W} \_ \text {mat }}\right)\right) \times 100,
\end{aligned}
$$

where $n_{\mathrm{C}}$ is the number of pikeperch in the correct group, $n_{\mathrm{w}}$ is the number of pikeperch in the wrong group, $\mathrm{imm}=$ immature group, and mat $=$ mature group.

The observed estimate of GSI was used as the first criterion to select a group of Lester models with similar $g$ value. After this, the AICc values were used, and if there were no differences in AICc values, then $l_{\text {diff }} \%$ and Corr $\%$ were applied.

\section{Results}

\section{Maturity and GSI}

In Sahajärvi, the youngest mature pikeperch were 5 years old; all 7-year-old and older pike- 
perch were mature in May 2017 (Table 2). Significant differences (one-sided $t$-test) were found in mean lengths and weights between immature and mature pikeperch at ages 5 and 6 (Table 3 ). As hypothesized, the mature pikeperch were longer (mean $19 \mathrm{~mm}$ and $38 \mathrm{~mm}$ for males and females, respectively) and heavier $(57 \mathrm{~g}$ and $107 \mathrm{~g}$ for males and females, respectively) than the immature ones at age 5 . These differences were much greater in females at age 6; this could not be tested in males, as there were no immature males at age 6 (Table 3 ).

Age and length at maturation differed between sexes when sex was used as a categorical variable in logistic regressions (models 1-4, e.g. length $\times$ sex M; Table 4). Models fitted for length

Table 3. Mean lengths (TL, $\mathrm{mm}$ ) and weights $(\mathrm{g})$ of male and female pikeperch at age 5 and 6 in relation to maturity in May 2017 in Sahajärvi. Minimum and maximum lengths and weights are in parentheses, and $p$ values are from one-sided $t$-test. Var = variance between groups, eq. = equal variances, uneq. $=$ unequal variances, $\mathrm{df}=\mathrm{degree}$ of freedom.

\begin{tabular}{|c|c|c|c|c|c|c|c|c|c|}
\hline Sex & Age & Size & Immature & $n$ & Mature & $n$ & Var & df & $p$ \\
\hline Male & 5 & length & $280(250-320)$ & 11 & $299(256-342)$ & 12 & eq. & 21 & 0.034 \\
\hline Male & 5 & weight & $175(122-266)$ & 11 & $232(136-367)$ & 12 & eq. & 21 & 0.014 \\
\hline Male & 6 & length & - & - & 342 (291-401) & 11 & - & - & - \\
\hline Male & 6 & weight & - & - & $371(187-648)$ & 11 & - & - & - \\
\hline Female & 5 & length & 282 (234-332) & 19 & $320(291-385)$ & 9 & eq. & 26 & 0.002 \\
\hline Female & 5 & weight & $185(93-308)$ & 19 & $292(178-500)$ & 9 & uneq. & 10.5 & 0.007 \\
\hline Female & 6 & length & 303 (272-322) & 3 & $362(302-427)$ & 7 & eq. & 8 & 0.035 \\
\hline Female & 6 & weight & $230(173-282)$ & 3 & $446(226-760)$ & 7 & eq. & 8 & 0.043 \\
\hline
\end{tabular}

Table 4. Model parameters in logistic regressions using maturity $(0=$ immature, $1=$ mature $)$ as the dependent variable, and age and length as the independent variables. In models $1-4$, sex is a categorical variable $(M=m a l e$, $\mathrm{F}=$ female). SE = standard error. Immature males $n=39$, mature males $n=25$, immature females $n=75$, mature females $n=29$.

\begin{tabular}{|c|c|c|c|c|c|c|c|}
\hline Model & Sex & Variable & $\begin{array}{c}\text { Parameter } \\
\text { estimate }\end{array}$ & SE & $X^{2}$ & $p>X^{2}$ & $\mathrm{AICC}$ \\
\hline \multirow[t]{3}{*}{1} & \multirow[t]{3}{*}{$M \& F$} & Intercept & -16.83 & 3.22 & 27.39 & $<0.001$ & \multirow[t]{3}{*}{84.4} \\
\hline & & length & 0.057 & 0.11 & 27.52 & $<0.001$ & \\
\hline & & length $\times \operatorname{sex} M$ & 0.003 & 0.01 & 7.48 & 0.006 & \\
\hline \multirow[t]{3}{*}{2} & \multirow[t]{3}{*}{$M \& F$} & Intercept & -13.95 & 2.98 & 21.96 & $<0.001$ & \multirow[t]{3}{*}{88.8} \\
\hline & & age & 2.71 & 0.58 & 21.75 & $<0.001$ & \\
\hline & & age $\times \operatorname{sex} M$ & 0.12 & 0.05 & 4.70 & 0.030 & \\
\hline \multirow[t]{4}{*}{3} & \multirow[t]{4}{*}{$M \& F$} & Intercept & -21.70 & 4.65 & 21.74 & $<0.001$ & \multirow[t]{4}{*}{73.5} \\
\hline & & age & 1.57 & 0.60 & 6.77 & 0.009 & \\
\hline & & length & 0.046 & 0.13 & 12.00 & $<0.001$ & \\
\hline & & length $\times$ sex $M$ & 0.003 & 0.01 & 6.63 & 0.010 & \\
\hline \multirow[t]{4}{*}{4} & \multirow[t]{4}{*}{$M \& F$} & Intercept & -22.09 & 4.78 & 21.40 & $<0.001$ & \multirow[t]{4}{*}{73.0} \\
\hline & & age & 1.67 & 0.61 & 7.44 & 0.006 & \\
\hline & & length & 0.045 & 0.13 & 11.72 & $<0.001$ & \\
\hline & & age $\times \operatorname{sex} M$ & 0.18 & 0.07 & 7.00 & 0.008 & \\
\hline \multirow[t]{3}{*}{5} & \multirow[t]{3}{*}{$M \& F$} & Intercept & -19.53 & 4.13 & 22.40 & $<0.001$ & \multirow[t]{3}{*}{79.1} \\
\hline & & age & 1.62 & 0.58 & 7.69 & 0.006 & \\
\hline & & length & 0.037 & 0.11 & 10.77 & 0.001 & \\
\hline \multirow[t]{2}{*}{6} & \multirow[t]{2}{*}{$M \& F$} & Intercept & -13.40 & 2.84 & 22.35 & $<0.001$ & \multirow[t]{2}{*}{91.7} \\
\hline & & age & 2.59 & 0.55 & 21.79 & $<0.001$ & \\
\hline \multirow[t]{2}{*}{7} & \multirow[t]{2}{*}{$M \& F$} & Intercept & -14.76 & 2.65 & 31.01 & $<0.001$ & \multirow[t]{2}{*}{91.0} \\
\hline & & length & 0.050 & 0.09 & 30.75 & $<0.001$ & \\
\hline
\end{tabular}


showed better fits than age based on the variable $X^{2}$ and AICc values in logistic regressions (model 1 vs. 2, model 6 vs. 7; Table 4). When males and females were analysed separately using only age or length, both of these variables were significant independent variables (models 8, 9, 11, 12; Table 5). Males were both shorter and younger at maturation than females (Fig. 1). The calculated values for $A_{50}$ and $L_{50}$ were 5.0 years $(95 \% \mathrm{CI}$ (confidence interval) $=3.6-7.2$ years $)$ and $279 \mathrm{~mm}$ $(95 \% \mathrm{CL}=205-360 \mathrm{~mm} \mathrm{TL})$ in males (models 8 and 9; Table 4), and 5.4 years $(95 \% \mathrm{CI}=3.7-6.3$ years $)$ and $310 \mathrm{~mm}$ TL $(95 \% \mathrm{CI}=240-380 \mathrm{~mm}$ TL) in females (models 11 and 12; Table 5). In females, both age and length were significant in the same logistic regression model (model 13; Table 5 and Fig. 2), whereas this was not the case in males (model 10; Table 5).

The mean GSI of males was 0.004 (or $0.4 \%$ ) ( $\mathrm{SD}=0.004, \min -\max =0.001-0.020)$ in May. There was no linear relationship between weight and GSI in males $\left(r^{2}=0.01, p>0.05, \mathrm{df}=30\right)$. The mean weight of mature males was $277.5 \mathrm{~g}$ $(\mathrm{SD}=122.5, \min -\max =115-648)$. In females, the mean GSI was 0.054 ( $\mathrm{SD}=0.023$, min$\max =0.010-0.086)$ and the mean weight of mature females was $420.8 \mathrm{~g}(\mathrm{SD} .=207.8$, min$\max =178-936)$. GSI increased towards heavier females $(\mathrm{GSI}=0.023+7.38 \mathrm{E}-5 \times$ body weight (g); $\left.r^{2}=0.43, p<0.001, \mathrm{df}=29\right)$ (Fig. 3).

\section{Growth based on the Lester model}

\section{Males and females}

The observed maximum GSI was 0.02 in males and when multiplied by 1.73 , the calculated estimate of $g$ was 0.035 , suggesting low investments in reproduction in males. The models between $A_{60}$ and $A_{90}$ gave smaller investments in reproduction ( $g=0.20-0.24)$ than those of $A_{10}$ to $A_{50}$ in which high values of $g$ were observed $(0.31-0.38)$ (Table 6). Within the models from $A_{60}$ to $A_{90}$, AICc values were almost identical and $l_{\text {diff }} \%$ was the lowest with $A_{80}$ (Fig. 4 and Table 6).

In females, different ages at maturity divided the data into three groups of models $\left(A_{10}-A_{20}\right.$, $A_{30}-A_{70}$, and $A_{80}-A_{90}$; Table 6). The maximum observed GSI in females was 0.086 and when multiplied by 1.73 , the direct calculated estimate for $g$ was 0.15 , suggesting low investments in reproduction also in females. The models between $A_{30}$ and $A_{70}$ gave the lowest $g$ values, and within these models, the lowest AICc was found for $A_{70}$ (Fig. 5a), while the lowest $g$ and $l_{\text {diff }} \%$ was for $A_{30}$ (Fig. 5c).

\section{Pooled data}

Different ages at maturity divided the pikeperch

Table 5. Logistic regression results with maturity as the dependent variable, and age and length as independent variables, separately for each sex. Firth's penalized likelihood approach was used in all models. SE = standard error. Immature males $n=39$, mature males $n=25$, immature females $n=75$, mature females $n=29$.

\begin{tabular}{|c|c|c|c|c|c|c|}
\hline Model & Sex & Variable & $\begin{array}{c}\text { Parameter } \\
\text { estimate }\end{array}$ & SE & $X^{2}$ & $p>X^{2}$ \\
\hline \multirow[t]{2}{*}{8} & \multirow[t]{2}{*}{ Male } & Intercept & -13.56 & 5.18 & 6.85 & 0.009 \\
\hline & & age & 2.74 & 1.03 & 7.14 & 0.008 \\
\hline \multirow[t]{2}{*}{9} & \multirow[t]{2}{*}{ Male } & Intercept & -13.22 & 3.70 & 12.77 & $<0.001$ \\
\hline & & length & 0.047 & 0.13 & 12.69 & $<0.001$ \\
\hline \multirow[t]{3}{*}{10} & \multirow[t]{3}{*}{ Male } & Intercept & -16.38 & 5.70 & 8.25 & 0.004 \\
\hline & & age & 1.48 & 0.98 & 2.29 & 0.130 \\
\hline & & length & 0.032 & 0.18 & 3.23 & 0.072 \\
\hline \multirow[t]{2}{*}{11} & \multirow[t]{2}{*}{ Female } & Intercept & -11.22 & 2.60 & 18.65 & $<0.001$ \\
\hline & & age & 2.07 & 0.50 & 17.46 & $<0.001$ \\
\hline \multirow[t]{2}{*}{12} & \multirow[t]{2}{*}{ Female } & Intercept & -16.08 & 3.83 & 17.59 & $<0.001$ \\
\hline & & length & 0.052 & 0.13 & 17.24 & $<0.001$ \\
\hline \multirow[t]{3}{*}{13} & \multirow[t]{3}{*}{ Female } & Intercept & -18.79 & 4.77 & 15.49 & $<0.001$ \\
\hline & & age & 1.04 & 0.50 & 4.29 & 0.038 \\
\hline & & length & 0.042 & 0.15 & 8.41 & 0.004 \\
\hline
\end{tabular}



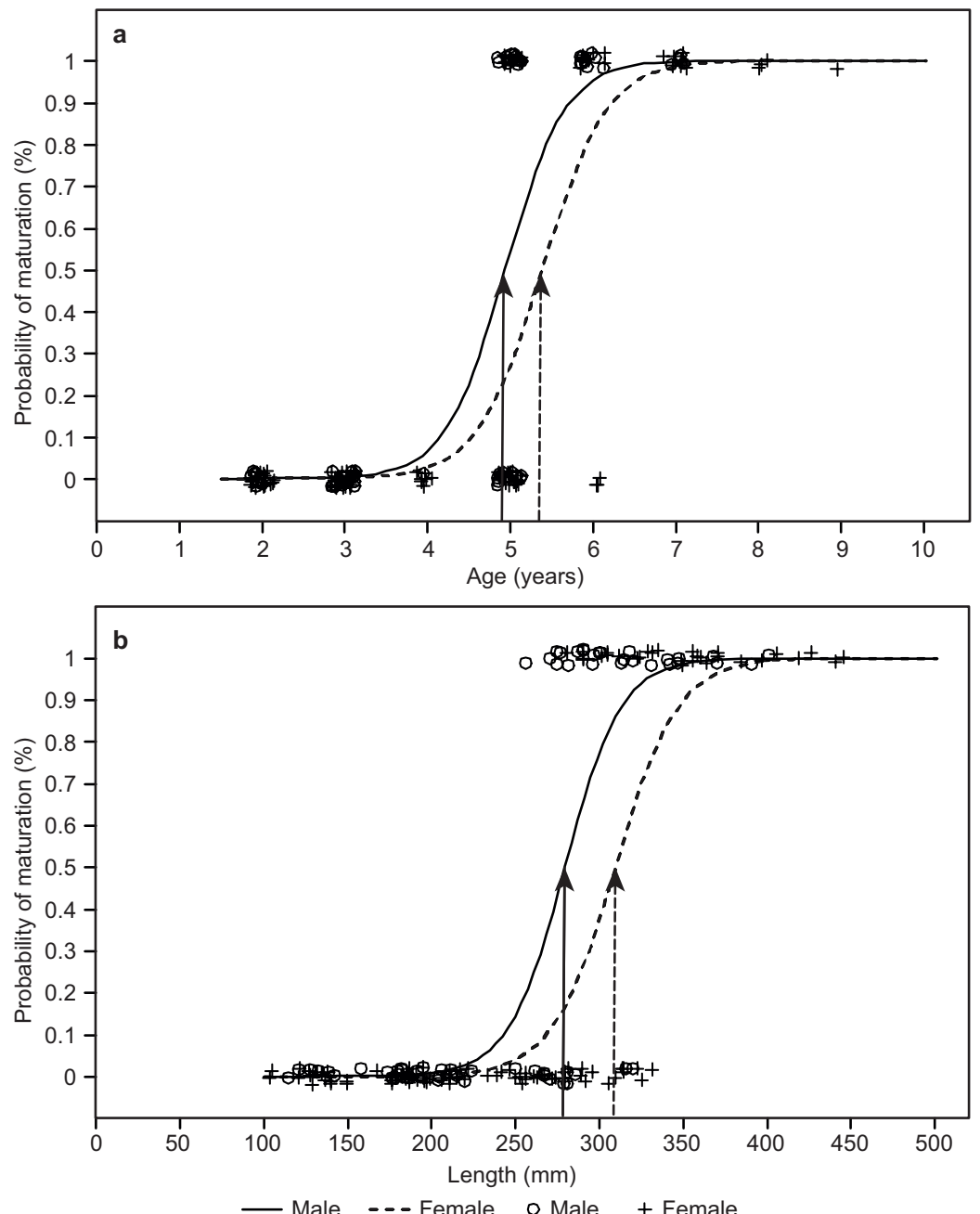

Fig. 1. Probability of maturity in relation to (a) age and (b) length. Arrows indicate age and length at $50 \%$ probability of maturity.

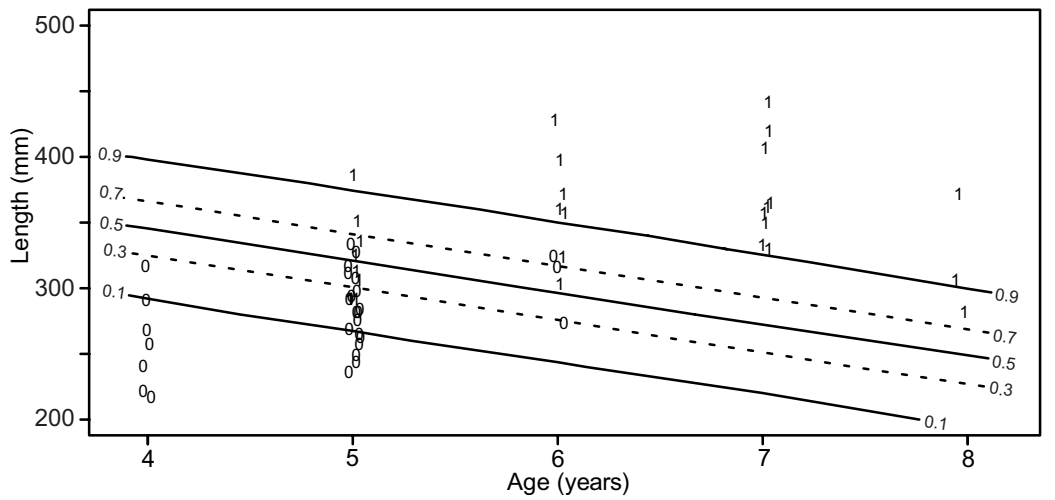

Fig. 2. Isopleths $(0.1-0.9)$ of the probability of maturity in females in relation to age and length (model 13; Table 5). 0 = immature female in May, 1 = mature female in May. Note that age markers are jittered.

into three groups of the same data in both immature and mature groups. These were from $A_{10}$ to $A_{30}$, from $A_{40}$ to $A_{80}$, and $A_{90}$ (Table 7). The mean GSI was calculated for the pikeperch in the mature group by using the observed maximum GSI values of 0.086 for females, 0.020 for males, and 0.053 for pikeperch with unknown sex. The calculated mean GSI was 0.050 in 
Fig. 3. Gonadosomatic index (GSI) in relation to weight (g) without gonads in females (open circles) and in males (pluses) in May.

Fig. 4. Lester model fit in age at $80 \%$ probability of maturity for males in Sahajärvi. Immature growth is marked with a broken line; mature growth with a solid line. (a) Age at $80 \%$ probability is 5.45 years, asymptotic length is $643 \mathrm{~mm} \mathrm{TL}$, and investment in reproduction $(g)$ is 0.22 . (b) Corresponding standardized residuals from Lester model a. $0=$ immature male, 1 = mature male, - = male pikeperch with unknown maturity. Note that age markers are jittered.
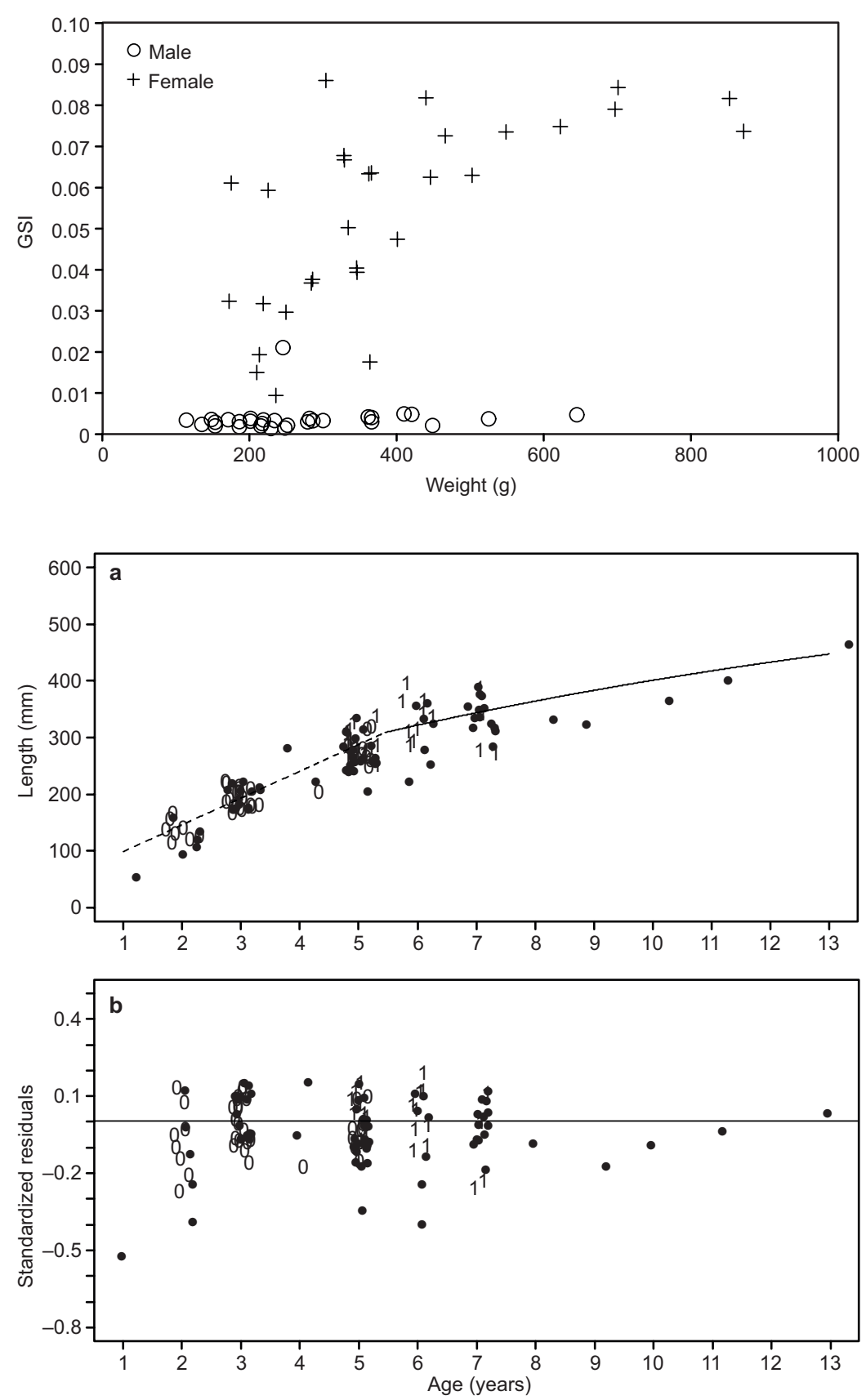

mature pikeperch in models from $A_{10}$ to $A_{30}$, 0.057 in $A_{40}$ to $A_{80}$, and 0.059 in $A_{90}$. When these mean GSI values were multiplied with 1.73 , the estimated values for $g$ were all close to 0.10 . The lowest $g$ values were found in Lester models from $A_{40}$ to $A_{80}(g=0.16-0.20)$. Within these, the lowest AICc and $l_{\text {diff }} \%$ values, and the highest Corr $\%$ were with $A_{80}$ (Fig. 6).

\section{Comparisons of Lester models}

Differences between the length at age estimates in those Lester models that gave small investments in reproduction and the observed mean lengths at age were small (Table 8). In males, the Lester model using $A_{80}$ gave length estimates that were between -7 and $9 \mathrm{~mm}$ TL of the observed 
t. வ வ வ வ வ

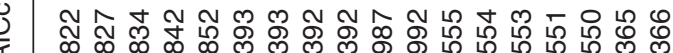
C FFFFF0000 N N mmmmm00

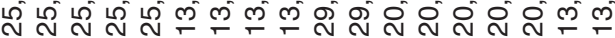

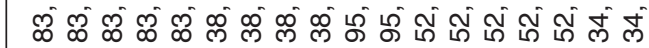

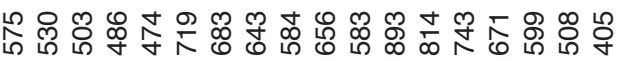

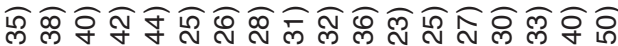

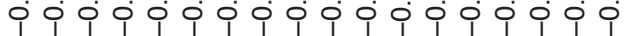
న్లి

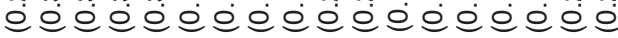
एె 000000000000000000

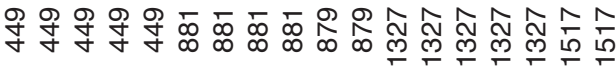

$\infty$ ص ํํ뉴

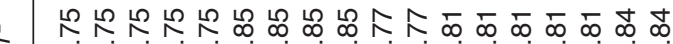

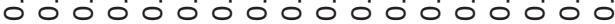

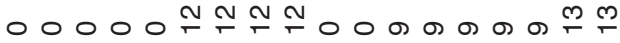
๙

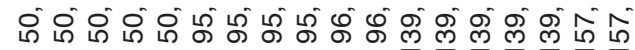

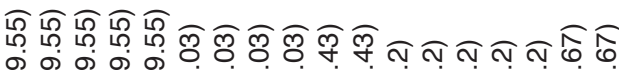

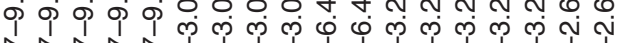

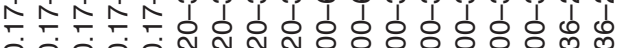

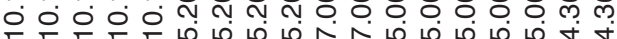
IIIIIIIIIIIIIIIIIIIII

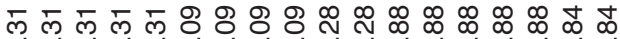
ip p i $_{1}$ T

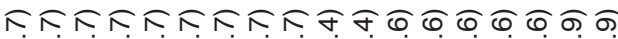

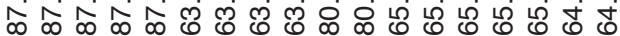

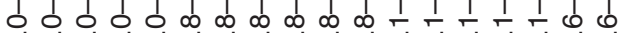

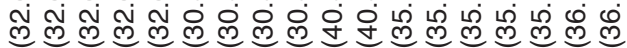
$\infty \infty \infty \infty \infty$ m m m m 0 \%

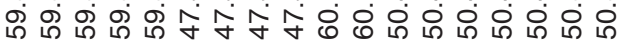

เ

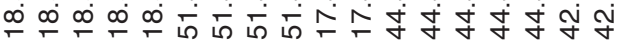

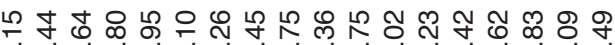

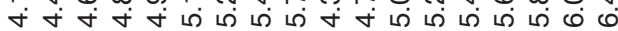

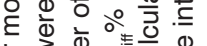

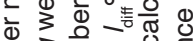

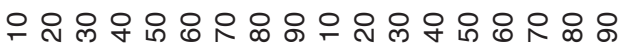


Fig. 5. Lester model fits in age at (a) $30 \%$ and (c) $70 \%$ probability of maturity for females; dashed line = immature growth, solid line $=$ mature growth with a solid line. (b) Standardized residuals from Lester model in a. (d) Standardized residuals from Lester model in c. $0=$ immature female, 1 = mature female, - = female pikeperch with unknown maturity status. Note that age markers are jittered.
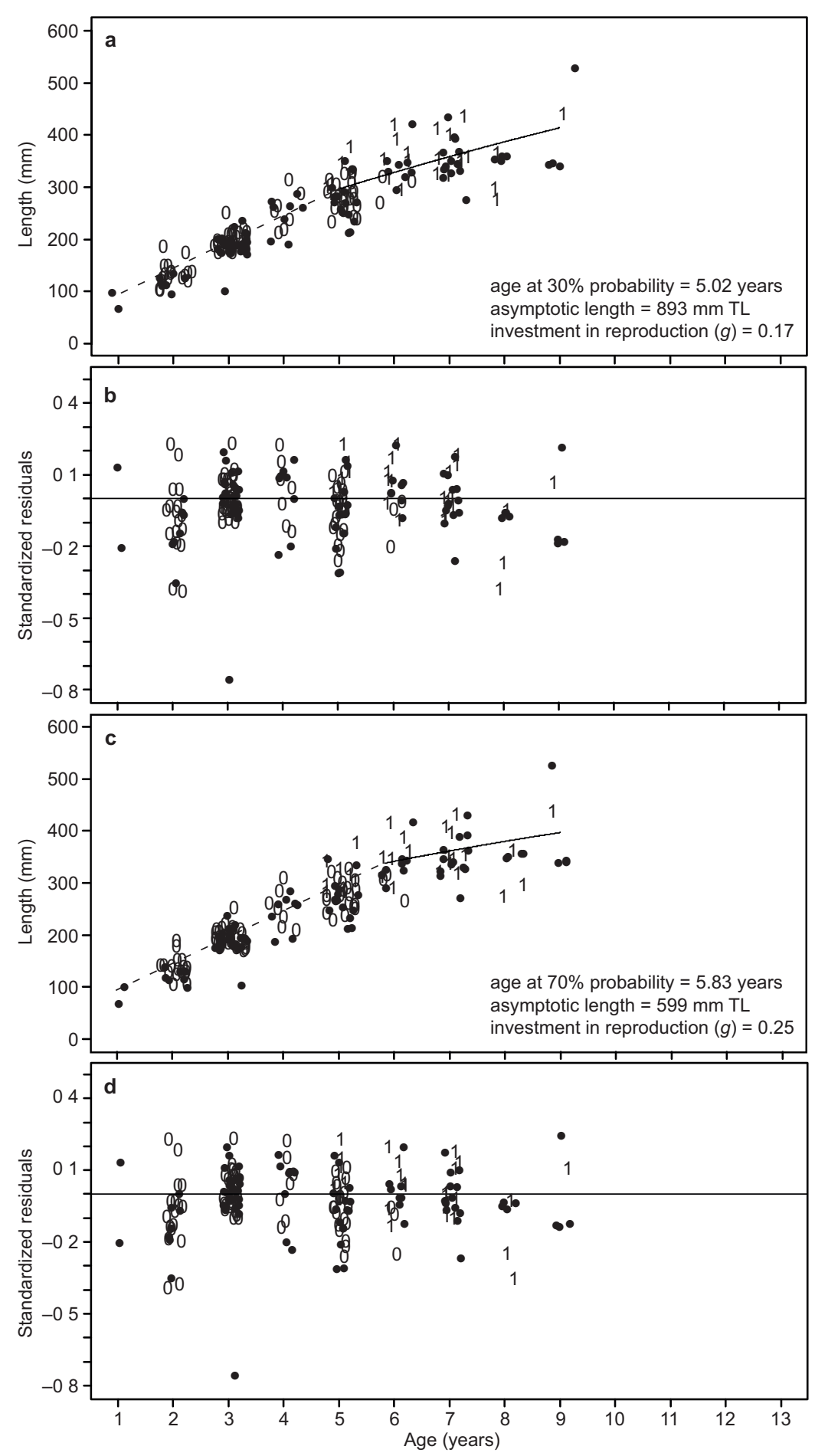

mean lengths at ages between 2 and 7 years $(n>$ 9, Table 8). In females, the length estimates for $A_{70}$ were between -13 and $10 \mathrm{~mm}$ of observed mean lengths at ages between 2 and 7 years, while in the pooled data, the $A_{80}$ gave length estimates that were between -14 and $13 \mathrm{~mm}$ 


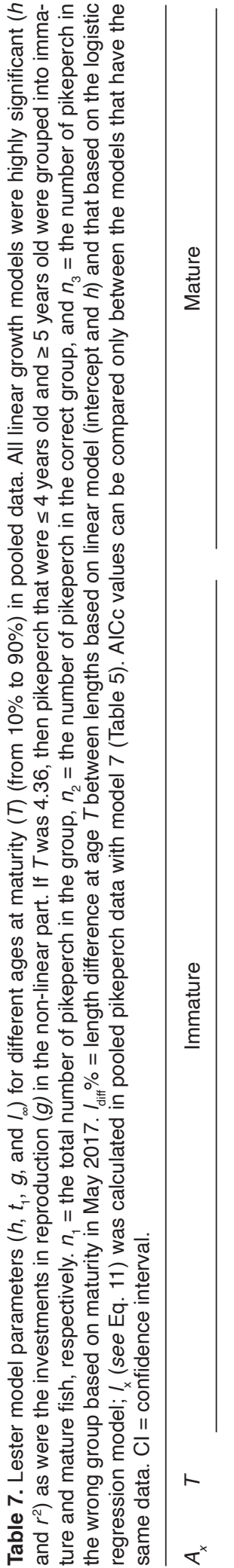

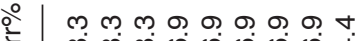
ஜ

ষัণ

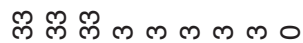
స

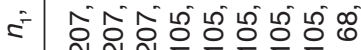
โิ ó ó ó ó ó o ócócó

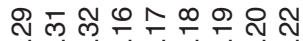

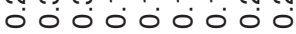

ن

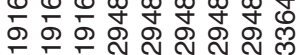

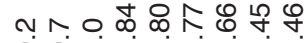
으읃ㄷㄷㄷㄷㄴ

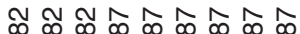

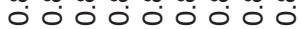

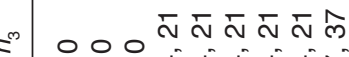

¿

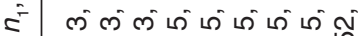

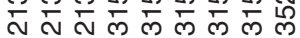

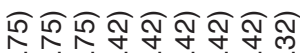
कं कं 0 0

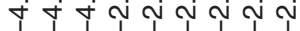
๑ ơ

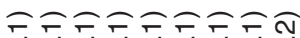

றா ற்

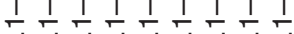

กิ่ กิ่

๑ 0 0 T T T T N

ชู่ ชู่ ชู่

흉

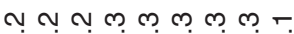

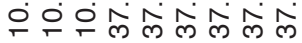

ஜ 守守

응으앙융ㅇㅇㅇㅇㅇ of observed lengths between 1 and 8 years (Table 8).

The Lester models showed small differences in lengths at age between $A_{10}$ and $A_{90}$ (Fig. 7). The maximum difference in Lester models that gave low investments in reproduction was $17 \mathrm{~mm}$ TL (in females between $A_{30}$ and $A_{70}$ at

Table 8. Length at age based on Lester models compared with observed mean lengths at age in males, females and pooled data. Age at maturity $(T)$ is based on the selected models (see Tables 6 and 7). Lengths at age 1-5 and 6-9 are for immature and mature growth, respectively. SE = standard error. All lengths are in $\mathrm{mm}$ TL.

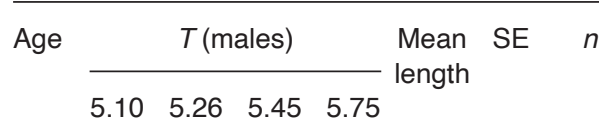

\begin{tabular}{rrrrrrrr}
\hline 1 & 99 & 99 & 99 & 99 & 65 & - & 1 \\
2 & 146 & 146 & 146 & 146 & 137 & 5.5 & 13 \\
3 & 193 & 193 & 193 & 193 & 200 & 3.3 & 33 \\
4 & 240 & 240 & 240 & 240 & 245 & 26.1 & 3 \\
5 & 288 & 288 & 288 & 288 & 286 & 4.0 & 45 \\
6 & 316 & 319 & 322 & 328 & 329 & 11.2 & 16 \\
7 & 341 & 342 & 344 & 347 & 346 & 9.0 & 17 \\
8 & 364 & 364 & 364 & 365 & 345 & - & 1 \\
9 & 386 & 385 & 383 & 381 & 335 & - & 1
\end{tabular}

\begin{tabular}{llllll}
\hline Age & \multicolumn{4}{c}{$T$ (females) } & Mean SE $n$ \\
\cline { 2 - 4 } & length & \\
5.02 & 5.23 & 5.42 & 5.62 & 5.83 &
\end{tabular}

\begin{tabular}{|c|c|c|c|c|c|c|c|c|}
\hline 1 & 95 & 95 & 95 & 95 & 95 & 96 & 16.1 & 2 \\
\hline 2 & 145 & 145 & 145 & 145 & 145 & 135 & 3.9 & 24 \\
\hline 3 & 195 & 195 & 195 & 195 & 195 & 200 & 2.8 & 55 \\
\hline 4 & 246 & 246 & 246 & 246 & 246 & 259 & 9.0 & 15 \\
\hline 5 & 296 & 296 & 296 & 296 & 296 & 291 & 5.4 & 43 \\
\hline 6 & 328 & 330 & 333 & 337 & 341 & 350 & 9.8 & 18 \\
\hline 7 & 358 & 359 & 359 & 360 & 361 & 369 & 8.3 & 22 \\
\hline 8 & 387 & 385 & 384 & 382 & 380 & 348 & 14.6 & 7 \\
\hline 9 & 414 & 410 & 406 & 402 & 397 & 413 & 36.7 & 5 \\
\hline Age & \multicolumn{5}{|c|}{$T$ (pooled data) } & \multirow{2}{*}{$\begin{array}{l}\text { Mean } \\
\text { length }\end{array}$} & \multirow[t]{2}{*}{ SE } & \multirow[t]{2}{*}{$n$} \\
\hline & 0 & 18 & 34 & 5.51 & 5.71 & & & \\
\hline
\end{tabular}

\begin{tabular}{rrrrrrrrr}
\hline 1 & 88 & 88 & 88 & 88 & 88 & 82 & 7.3 & 13 \\
2 & 139 & 139 & 139 & 139 & 139 & 132 & 2.0 & 83 \\
3 & 191 & 191 & 191 & 191 & 191 & 201 & 2.0 & 98 \\
4 & 242 & 242 & 242 & 242 & 242 & 256 & 8.0 & 19 \\
5 & 293 & 293 & 293 & 293 & 293 & 287 & 3.0 & 102 \\
6 & 327 & 328 & 331 & 333 & 337 & 345 & 7.6 & 37 \\
7 & 358 & 359 & 360 & 362 & 364 & 362 & 6.7 & 40 \\
8 & 389 & 389 & 389 & 389 & 390 & 377 & 13.8 & 13 \\
9 & 417 & 416 & 415 & 414 & 413 & 400 & 32.7 & 6 \\
\hline
\end{tabular}


Fig. 6. (a) Lester model fits in age at $80 \%$ probability of maturity for pooled pikeperch, and (b) standardized residuals from Lester model. Dashed line = immature growth, solid line $=$ mature growth $0=$ immature male or female, $1=$ mature male or female, $\bullet=$ pikeperch with unknown maturity status. Note that age markers are jittered.
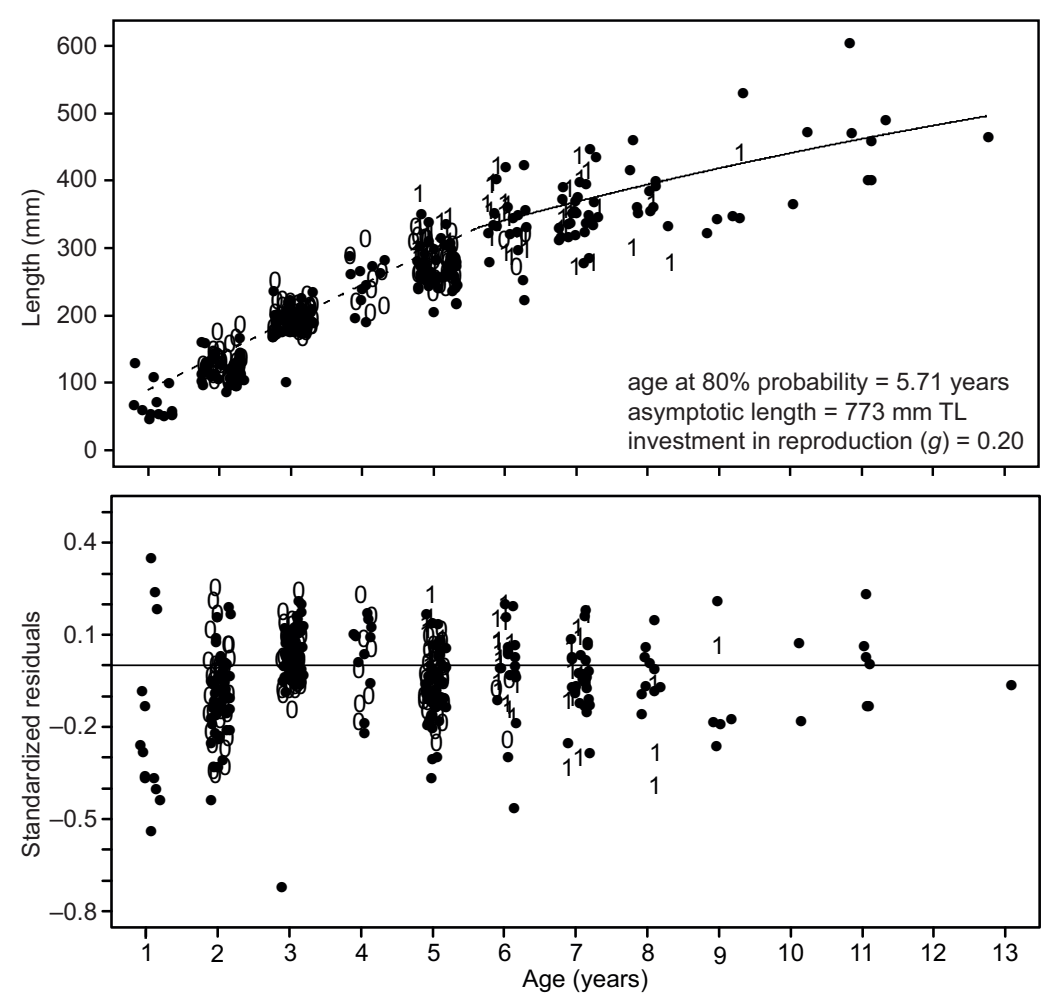

age 6; Table 8). However, the differences in asymptotic lengths were much larger in Lester models that gave low investments in reproduction. In males, the asymptotic lengths were between $719 \mathrm{~mm}$ and $584 \mathrm{~mm}$ TL in models from $A_{60}$ to $A_{90}$, between $893 \mathrm{~mm}$ and $599 \mathrm{~mm}$ TL in $A_{30}$ to $A_{70}$ in females, and between 950 and $773 \mathrm{~mm}$ TL in $A_{40}$ to $A_{80}$ in the pooled data, respectively (Tables 6 and 7).

\section{Discussion}

The results showed that the onset of maturation in pikeperch depends on both age and length, and that these differed significantly between the sexes. The observed GSI values for both sexes were low, and these were used to select the Lester models that also gave low values of investments in reproduction $(g)$. Low investments were found in Lester models in which the age at maturity varied between 5 and 6 years. In these models, the differences in mean lengths at age between different models were small, and were also small when compared with the observed mean lengths at age.

In Sahajärvi, the age at maturity was spread over two years, which seems typical for pikeperch in other lakes in Finland as well as in southern Europe (Raikova-Petrova \& Živkov 1998, Lappalainen et al. 2003, Ruuhijärvi et al. 2005, Olin et al. 2018). In Sahajärvi, the estimated age at $50 \%$ probability of maturity of female pikeperch (5.4 years) was within the range that has been shown for six other lakes in Finland (4.2-6.9 years) (Olin et al. 2018). On the other hand, the length at $50 \%$ probability of maturity was smaller (male $279 \mathrm{~mm}$ TL, female $310 \mathrm{~mm} \mathrm{TL}$ ) than in other Finnish lakes (male 340-360 mm TL, female 403-460 mm TL) (Lehtonen \& Miina 1988, Olin et al. 2018). In Sahajärvi, females at maturation were both older and longer than males at maturation, which seems to be typical for the Sander and Perca species (Scott \& Crossman 1973, Raikova-Petrova \& Živkov 1998, Rennie et al. 2008, Venturelli et al. 2010, Olin et al. 2018). In Europe, the age at maturity in both sexes of pikeperch was from 

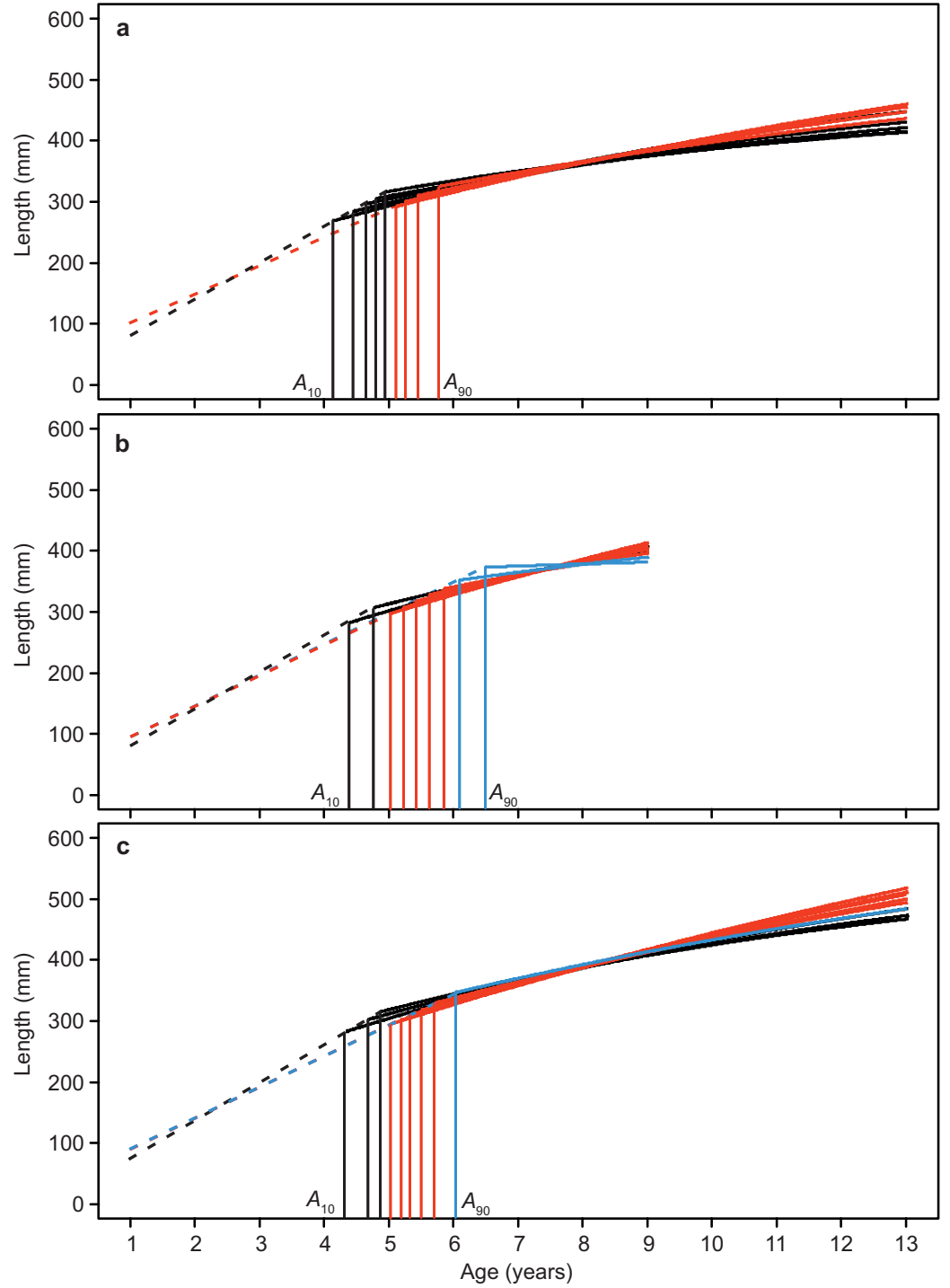

Fig. 7. Pikeperch growth based on Lester models in (a) males, (b) females and (c) pooled data with different age at probability of maturity $\left(A_{10}-A_{90}\right)$. Horizontal lines indicate ages from $10 \%$ to $90 \%$ probabilities of maturity.
1 to 9 years, while the maximum age at maturity in females was 10 years. In southern Europe, where the growth of pikeperch was more rapid, the age at maturity was lower than in pikeperch that were closer to the northern distribution range (Raikova-Petrova \& Živkov 1998). Similarly, in another Sander species, walleye (Sander vitreus), the growth was faster and the age at maturity was lower in warmer than in colder lakes (Venturelli et al. 2010).

In Sahajärvi, pikeperch growth was slow (Milardi et al. 2011), which is probably the reason for the observed smaller length at 50\% probability of maturity than in other studies
(Lehtonen \& Miina 1988, Olin et al. 2018). In perch (Perca fluviatilis), the age at maturity was similar between populations showing normal and stunted growth, but the length at maturity was smaller in populations showing stunted growth (Heibo et al. 2005). The reasons for the slow growth of pikeperch in Sahajärvi are not known, but the abundance of small pikeperch has been very high (Milardi et al. 2011). Notably, a large part of the diet was non-piscine, which is uncharacteristic for the typically piscivorous pikeperch (Vinni et al. 2009, Milardi et al. 2011). Venturelli et al. (2010) showed that in populations of walleye that have experienced 
dramatic changes in abundances, there was an increase in the immature growth rate when the abundance was lower.

The best Lester models were selected based on the observed GSI in May and investments in reproduction $(g)$. GSI values were low for both sexes in Sahajärvi, which have been observed also in other pikeperch populations, and were low when compared for example with perch (Uysal et al. 2006, M'Hetli et al. 2011, Fontaine et al. 2015). Therefore, the Lester models that gave low $g$ values were selected. The lowest $g$ values in Lester models were found with age at maturity from 5.10 to 5.75 years in males, and from 5.02 to 5.83 years in females. In these models, the investments in reproduction ranged from 0.20 to 0.24 in males, and from 0.17 to 0.25 in females. In the pooled data, the lowest $g$ values between 0.16 and 0.20 were found for age at maturity between 5.02 and 5.71 years. Vainikka et al. (2017) showed similar $g$ values, between 0.16 and 0.24 , for the sex-pooled pikeperch data from six lakes in Finland.

The energy ratio value used here was based on that of females in the original articles reviewed by Lester et al. (2004). There are only few energy ratio estimates available for males. In yellow perch (Perca flavescens) males, the ratio value was 0.85 (the energy density of testes to the energy density of the whole fish (Rennie 2003)), and in salmon (Salmo salar) males 1.00 (Jonsson et al. 1991). Therefore, the used energy ratio of 1.73 could be too high for males, but this had no effects on the selection of the best Lester models, because the lowest $g$ value was 0.20 in males. Notably, additional costs in reproduction come from guarding the eggs of pikeperch males in the nest after spawning. This behaviour ceases when the larvae are hatched (Lappalainen et al. 2003).

Fitting the Lester model requires knowledge of the age at maturity. Here, the best results were obtained with age at maturity between 5.45 and 5.83 years or with $A_{70}$ in both males and females, and with $A_{80}$ in the pooled data. The greatest hindrance for estimating the growth of mature fish was that the number of large and old pikeperch were low in our data (Minte-Vera et al. 2016). The lack of such data affects the estimation of the parameter that is probably the most interest- ing and has the highest importance (investment in reproduction), and affects the estimation of the asymptotic lengths.

The low number of old and large pikeperch in Sahajärvi is due to gillnet fishing. In many lakes in Finland, including Sahajärvi, recreational fishermen can use gillnets after purchasing required fishing permits. The minimum allowed mesh size of gillnets is $60 \mathrm{~mm}$ (knot to knot), while the minimum legal size limit of pikeperch is $420 \mathrm{~mm}$ TL. Gillnet fishing was suggested to be the cause for the low number of pikeperch larger than $420 \mathrm{~mm}$ in the lake (Milardi et al. 2011). The same was noted here, as the number of large (> $420 \mathrm{~mm} \mathrm{TL}$ ) was also low, which makes it difficult to estimate the growth of mature pikeperch. However, the growth of immature, juvenile pikeperch can be estimated more reliably, because the number of immature fish is generally high enough, and their abundance is not directly related to fishing that targets mature fish. Here, the best estimates of the immature growth rate per year was $47.3 \mathrm{~mm}$ TL in males, $50.4 \mathrm{~mm}$ TL in females, and $51.1 \mathrm{~mm}$ TL in the pooled data. These values are lower than estimated based on the Lester model in other Finnish lakes (55.6$97.1 \mathrm{~mm}$ TL) (Vainikka et al. 2017).

\section{Acknowledgements}

This research was funded by the Jenny and Antti Wihuri Foundation and Centre for Economic Development, Transport and the Environment, southwest Finland. We thank prof. Anssi Vainikka, and two anonymous reviewers for their comments on the earlier versions of this manuscript.

\section{References}

Antila, E., Stenbäck, H. \& Teräväinen, T. 1988: Artificially improved breeding of captive pike-perch (Stizostedion lucioperca) females achieved using a gonadotropinreleasing analogue. - Finnish Fisheries Research 7: 75-83.

Bagenal, T. B. \& Tesch, F. W. 1978: Age and growth. In: Bagenal, T. (ed.), Methods for assessment of Fish Production in Freshwaters, IBP Handbook 3: 101-136. Blackwell Scientific Publications, Oxford.

Barot, S., Heino, M., O’Brien, L. \& Dieckmann, U. 2004: Estimation of reaction norm for age and size at maturity with missing first-time spawner data. - Evolutionary Ecology Research 6: 659-678. 
Day, T. \& Taylor, P. D. 1997: von Bertalanffy's growth equation should not be used to model age and size at maturity. - The American Naturalist 149: 381-393.

Enberg, K., Dunlop, E. S. \& Jørgensen, C. 2008: Fish growth. - In: Goldstein, M. I. (ed.), Encyclopedia of ecology: 1564-1572. Academic Press, Oxford.

Fontaine, P., Wang, N. \& Hermelink, B. 2015: Broodstock management and control of the reproductive cycle. In: Kestemont, P., Dabrowski, K. \& Summerfelt, R. C. (eds), Biology and culture of percid fishes: 103-122. Springer, Dordrecht.

Heibo, E., Magnhagen, C. \& Vøllestad, L. A. 2005: Latitudinal variation in life-history traits in Eurasian perch. Ecology 86: 3377-3386.

Heinze, G. 2006: A comparative investigation of methods for logistic regression with separated or nearly separated data. - Statistics in Medicine 25: 4216-4226.

Hermelink, B., Wuertz, S., Trubiroha, A., Rennert, B., Kloas, W. \& Schulz, C. 2011: Influence of temperature on puberty and maturation of pikeperch, Sander lucioperca. - General and Comparative Endocrinology 172: 282-292.

Honsey, A. E., Staples, D. F. \& Venturelli, P. A. 2017: Accurate estimates of age at maturity from the growth trajectories of fishes and other ectotherms. - Ecological Applications 27: 182-192.

Jonsson, N., Jonsson, B. \& Hansen, L. P. 1991: Energetic cost of spawning in male and female Atlantic salmon (Salmo salar L.). - Journal of Fish Biology 39: 739-744.

Lappalainen, J. \& Malinen, T. 2002: Effects of area and location on pikeperch yields in Finnish lakes. - In: Cowx, I. G. (ed.), Management and ecology of lake and river fisheries: 35-45. Blackwell Science, Oxford.

Lappalainen, J., Dörner, H. \& Wysujack, K. 2003: Reproduction biology of pikeperch (Sander lucioperca (L.)) - a review. - Ecology of Freshwater Fish 12: 95-106.

Lehtonen, H. 1987: Selection of minimum size limit for pikeperch (Stizostedion lucioperca) in the coastal waters of Finland. - In: Kullander, S. O. \& Fernholm, B. (eds.), Proceedings of the Fifth Congress of European Ichthyologists, Stockholm, 1985: 351-355. Department of Vertebrate Zoology, Swedish Museum of Natural History.

Lehtonen, H. \& Miina, T. 1988: Minimum size of pike-perch (Stizostedion lucioperca (L.)) for exploitation in Lake Lohjanjärvi, Southern Finland. - Aqua Fennica 18: 157-164.

Lester, N. P., Shuter, B. J. \& Abrams, P. A. 2004: Interpreting the von Bertalanffy model of somatic growth in fishes: The cost of reproduction. - Proceedings of the Royal Society of London B 271: 1625-1631.

M'Hetli, M., Ben Khemis, I., Hamza, N., Turki, B. \& Turki, O. 2011: Allometric growth and reproductive biology traits of pikeperch Sander lucioperca at the southern edge of its range. - Journal of Fish Biology 78: $567-579$

Minte-Vera, C. V., Maunder, M. N., Casselman, J. M. \& Campana, S. E. 2016: Growth functions that incorporate the cost of reproduction. - Fisheries Research 180: 31-44.

Milardi, M., Lappalainen, J., Malinen, T., Vinni, M. \& Ruuhi- järvi, J. 2011: Problems in managing a slow-growing pikeperch (Sander lucioperca (L.)) population in Southern Finland. - Knowledge and Management of Aquatic Ecosystems 400, 08, https://doi.org/10.1051/kmae/2011010.

Nagashima, K. \& Sato, Y. 2017: Information criteria for Firth's penalized partial likelihood approach in Cox regression models. - Statistics in Medicine 36: 3422-3436.

Olin, M., Vainikka, A., Roikonen, T., Ruuhijärvi, J., Huuskonen, H., Kotakorpi, M., Vesala, S., Ala-Opas, P., Tiainen, J., Nurminen, L. \& Lehtonen, H. 2018: Trait-related variation in the reproductive characteristics of female pikeperch (Sander lucioperca). — Fisheries Management and Ecology 25: 220-232.

Raikova-Petrova, G. \& Živkov, M. 1998: Maturity, spawning and sex ratio of pike perch, Stizostedion lucioperca (L.), in two Bulgarian reservoirs as compared to other European habitats. - Journal of Applied Ichthyology 14: $31-35$.

Rennie, M. D. 2003: Mercury in aquatic foodwebs: refining the use of mercury in energetics models of wild fish populations. - M.Sc. thesis, University of Toronto, Ontario.

Rennie, M. D. \& Venturelli, P. A. 2015: The ecology of lifetime growth in percid fishes. - In: Kestemont, P., Dabrowski, K. \& Summerfelt, R. C. (eds), Biology and culture of percid fishes: 499-536. Springer, Dordrecht.

Rennie, M. D., Purchase, C. F., Lester, N., Collins, N. C., Shuter, B. J. \& Abrams, P. A. 2008: Lazy males? Bioenergetic differences in energy acquisition and metabolism help to explain sexual size dimorphism in percids. Journal of Animal Ecology 77: 916-926.

Ruuhijärvi, J., Salminen, M. \& Nurmio, T. 1996: Releases of pikeperch (Stizostedion lucioperca (L.)) fingerlings in lakes with no established pikeperch stock. - Annales Zoologici Fennici 33: 553-567.

Ruuhijärvi, J., Malinen, T., Ala-Opas, P. \& Tuomaala, A. 2005: Fish stocks of Lake Vesijärvi: from nuisance to flourishing fishery in 15 years. - Internationale Vereinigung für theoretische und angewandte Limnologie: Verhandlungen 29: 384-389.

SAS 2015: SAS/STAT ${ }^{\circledR} 14.1$ User's Guide. - SAS Institute Inc., Cary, NC.

Scott, W. B. \& Crossman, E. J. 1973: Freshwater fishes of Canada. - Fisheries Research Board of Canada, Ottawa.

Shuter, B. J., Lester, N. P., LaRose, J., Purchase, C. F., Vascotto, K., Morgan, G., Collins N. C. \& Abrams, P. A. 2005: Optimal life histories and food web position: linkages among somatic growth, reproductive investment, and mortality. - Canadian Journal of Fisheries and Aquatic Sciences 62: 738-746.

Teletchea, F., Gardeur, J. N., Psenicka, M., Kaspar, V., Le Doré, Y., Linhart, O. \& Fontaine, P. 2009: Effects of four factors on the quality of male reproductive cycle in pikeperch Sander lucioperca. - Aquaculture 291: 217-223.

Tolonen, A., Kjellman, J. \& Lappalainen, J. 1999: Diet overlap between burbot (Lota lota (L.)) and whitefish (Coregonus lavaretus (L.)) in a subarctic lake. - Annales Zoologici Fennici 36: 205-214.

Uysal, K., Yerlikaya, A., Aksoylar, M., Yöntem, M. \& Ulupinar, M. 2006: Variations in fatty acids composition 
of pikeperch (Sander lucioperca) liver with respect to gonad maturation. - Ecology of Freshwater Fish 15: $441-445$.

Vainikka, A., Olin, M., Ruuhijärvi, J., Huuskonen, H., Eronen, R. \& Hyvärinen, P. 2017: Model-based evaluation of the management of pikeperch (Sander lucioperca) stocks using minimum and maximum size limits. - Boreal Environment Research 22: 187-212.

Venturelli, P. A., Lester, N. P., Marshall, T. R. \& Shuter, B. J. 2010: Consistent patterns of maturity and density-dependent growth among populations of walleye (Sander vitreus): application of the growing degree-day metric. - Canadian Journal of Fisheries and Aquatic Sciences 67: 1057-1067.
Wilson, K. L., Honsey, A. E., Moe, B. \& Venturelli, P. 2018: Growing the biphasic framework: Techniques and recommendations for fitting emerging growth models. Methods in Ecology and Evolution 9: 822-833.

Winkler, H. M., Klinkhardt, M. B. \& Buuk, B. 1989: Zur Fruchtbarkeit und Reifeentwicklung am Zander (Stizostedion lucioperca (L.)) aus Brackgewässern der südlichen Ostsee. - Wissenschaftliche Zeitschrift der Universität Rostock 38 (N-Reihe): 31-37. [In German with Russian and English summaries].

Vinni, M., Lappalainen, J., Malinen, T. \& Lehtonen, H. 2009: Stunted growth of pikeperch Sander lucioperca in Lake Sahajärvi, Finland. - Journal of Fish Biology 74: 967-972. 